\title{
On Becoming a Rooster: Zhuangzian Conventionalism and the Survival of Death
}

\author{
Michael Tze-Sung Longenecker
}

***This is a pre-print of an article forthcoming in Dao: A Journal of Comparative Philosophy

\begin{abstract}
The Zhuangzi 莊子 depicts persons as surviving their deaths through the natural transformations of the world into very different forms - such as roosters, cart-wheels, rat livers, etc. It's common to interpret these passages metaphorically. But in this paper, I suggest employing a "Conventionalist" view of persons that says whether a person survives some event is not merely determined by the world, but is partly determined by our own attitudes. On this reading, Zhuangzi's many teachings urging us to embrace transformation are not merely a psychological aid for dealing with death, but also serve as a tool for literally surviving it.
\end{abstract}

Keywords Zhuangzi 莊子; Conventionalism; Personal Identity; Self; Death

\section{Introduction}

In the Zhuangzi 莊子 chapter 6 "The Great and Venerable Teacher (Dazongshi 大宗師)", we encounter two stories of people who are thought to transform beyond their human form. One such story is this:

\footnotetext{
All at once, Master Yu fell ill. Master Si went to ask how he was. "Amazing!" said Master Yu. "The Creator is making me all crookedly like this! My back sticks up like a hunchback, and my vital organs are on top of me. My chin is hidden in my navel, my shoulders are up above my head, and my pigtail points at the sky. It must be some dislocation of the yin and yang!"
} 
Yet he seemed calm at heart and unconcerned. Dragging himself haltingly to the well, he looked at his reflection and said, "My, my! So the Creator is making me all crookedly like this!"

"Do you resent it?" asked Master Si.

"Why no, what would I resent? If the process continues, perhaps in time he'll transform my left arm into a rooster. In that case I'll keep watch during the night. Or perhaps in time he'll transform my right arm into a crossbow pellet, and I'll shoot down an owl for roasting. Or perhaps in time he'll transform my buttocks into cart-wheels. Then, with my spirit for a horse, I'll climb up and go for a ride. What need will I ever have for a carriage again?" (Watson 2013: 47-8)

We all know that bodies undergo great transformation. Our body ages, eventually dies, then undergoes decomposition, leaving the molecules that made up the body to disperse, and eventually become integrated - via absorption, consumption, etc.- with other plants and animals (such as roosters), or artifacts (such as cart-wheels), etc. But part of what's striking about this passage is that Master Yu doesn't just take his molecules to take on these new forms, but also he himself takes on those new forms. For he doesn't merely say that if his left arm turned into a rooster, it would keep watch during the night—rather, he uses the first person pronoun "I ( $y u$ 予)" to indicate that it would be he himself who would be the rooster.

The story of Master $\mathrm{Yu}$ is ambiguous between whether we are to imagine his arm turning into a rooster while Master $\mathrm{Yu}$ is still alive in his human form, or only after he has died. But the story immediately following strongly indicates that (at least in part) what's in mind is transformation after one's death: 
Suddenly Master Lai grew ill. Gasping and wheezing, he lay at the point of death. His wife and children gathered round in a circle and began to cry. Master Li, who had come to ask how he was, said "Shoo! Get Back! Don't disturb the process of change!"

Then he leaned against the doorway and talked to Master Lai. "How marvelous the Creator is! What is he going to make out of you next? Where is he going to send you? Will he make you into a rat's liver? Will he make you into a bug's arm?" (Watson 2013: 48)

Clearly the transformation into a rat's liver or bug's arm is conceived as happening after Master Lai's death. So the stories of Masters Yu and Lai taken together indicate that people can continue to exist beyond their own death in a naturalistic sort of way. Such survival doesn't require the existence of a supernatural realm that we go to after death. Nor does it require the existence of some immaterial soul that can be reincarnated in different forms. Rather, the Zhuangzi treats their survival as consisting in their continued existence on earth as one (or more) of the myriad thingssuch as roosters, cart-wheels, bug arms, etc. (The view also seems to imply that one can exist as a scattered object. For even if the molecules of one's decomposed body scatter in different directions, the text seems to suggest that those scattered molecules would still be parts of Master Yu. Thus, if Master Yu simultaneously has both a rooster and a spatially disconnected crossbow pellet as parts, he could simultaneously keep watch during the night and shoot down an owl for roasting. $)^{1}$

This view is highly counter-intuitive. We ordinarily think that we cease to exist at death. And even if our corpse were to turn into a rooster, that rooster wouldn't be oneself. ${ }^{2}$ For this reason, it's

\footnotetext{
${ }^{1}$ One might think this idea is absurd, for Master Yu cannot be two different objects. But the claim here is not that he would be two objects, but only that he is one object with at least two (spatially disconnected) parts.

${ }^{2}$ We might make the story more believable if we assume that Zhuangzi is saying that, were Master Yu's body turned into a rooster, the rooster wouldn't have any of Master Yu's memories or personality, but would just have the
} 
not surprising that many scholars interpret these stories metaphorically, denying that the Zhuangzi intends anything about the survival of death. For instance, Jung H. Lee says "Ziyu [Master Yu] will not enjoy another life as a rooster or owl" (Lee 2014: 114) and he further claims that "ultimately, Zhuangzi suggests that a transcendence of the fear of death can only commence with the recognition that one's personal identity eventually expires (a notion unthinkable for many ancient Chinese) as part of the transformations of the Dao" (Lee 2014: 119). Louis Komjathy likewise says that the passages "seem to indicate that death is the dissolution of self, the separation of the various elements of personhood. There is no personal post-mortem existence, no personal survival after death" (Komjathy 2013: 140). Kim-chong Chong, referring to the stories of Masters Yu and Lai, says that "[Xunzi's] definition of hua (化), or transformation, opposes the way that Zhuangzi uses the term.... [According to Xunzi] something may be said to have been transformed only when it is one and the same entity that has undergone a process of change" (Chong 2016: 501). Thus, Chong is assuming that, in Master Yu's story, it would not be one and the same entity that is a human at one time and a rooster at the other. ${ }^{3}$ Mark Berkson also denies that there is a self that persists through the change, instead holding that "there is simply an ongoing series of transformation" (Berkson 2019: 26). Xiaogan Liu takes Master Yu's hypothesizing as mere "imagination", taking the story to not have implications concerning our ability to survive death:

no matter how depressing [Master Yu's] health may be, he can always shift it to a positive, even optimistic mode through curiosity and imagination. What the author wants to express

psychology of a normal rooster. Nonetheless, it would still be counter-intuitive to hold that such Master Yu himself would be that rooster.

${ }^{3}$ Notice that I'm not claiming that Chong accepts Xunzi's definition. But in the quote, Chong indicates that Xunzi's definition conflicts with the way Zhuangzi uses the term hua; my claim is just that Chong would not think that such a conflict arises if he interpreted Zhuangzi as holding that it is the same entity that is at one time a human, and then at another time a rooster. 
is clear: by learning to keep your mind and mood at ease towards adversity people can mount the springboard from which to jump into a sphere of spiritual freedom. (Liu 2015: 200-1)

Others likewise shy away from drawing conclusions about our ability to survive. Mercedes Valmisa says "the key teaching in this story is that, however big the changes, even if they involve terminal disease, we should not fear or hate them but adapt to them and see in them a window of opportunity" (Valmisa 2015: 8). And Mary Bockover says "these seem like absurd possibilities, I think the point is this: life is unpredictable and can do anything. The question is, what will we make of it? Will we live virtuously or the best we can despite what life might throw at us?" (Bockover 2020: 53).

In this paper, I will go against the trend and instead suggest interpreting the Zhuangzi as literally holding that we can survive our death in the above envisioned ways. In order to both provide a framework for doing so and lend credibility to such a reading, I will draw from recent work in metaphysics that holds that persons are in some sense "conventional". On this view, whether we survive an event (at least sometimes) isn't wholly determined by the world, but is at least in part determined by our attitudes. In particular, I suggest reading Zhuangzi as holding a sort of Conventionalism that is both extreme and nuanced: it's extreme because it holds that, by undergoing a "freeing of the bound (xian jie 縣解)", one's attitudes are changed in such a way that one literally survives death, and undergoes the various transformations of their body; and it's nuanced because only one aspect of oneself — what Zhuangzi calls the " $w u$-self"-can survive death in this way. In section 2 I further explicate this Conventionalism about personal identity, and in sections 3 and 4 I explain and defend the Conventionalist view that I attribute to Zhuangzi. 
Finally, I draw out connections between this Conventionalist reading and other passages in the Zhuangzi in section 5.

\section{Personal Identity and Conventionalism}

Commonsense tells us that we persist over time. I not only exist today, but I also existed yesterday, and a year ago, and much further back to when I was just a wee baby. This implies that there are changes that I can survive: I survive the change from being a baby to being an adult. But commonsense also tells us that there are events that we don't survive, such as being burnt to a crisp and having one's ashes dispersed across the universe. ${ }^{4}$ But what criteria of personal identity accounts for the fact that I can survive some kinds of changes, but not others? That is, what are the necessary and sufficient conditions for a person at one time being identical to an entity ${ }^{5}$ at another time? Reflection on this question has brought philosophers to two main candidate answers. The first is a psychological criterion-for instance, John Locke's (1694) points to memory (though see Parfit's (1984) for a more sophisticated view). Thus, since I'm psychologically continuous in the right way — such as via memory — with the baby that lived some years ago, I'm identical to that baby. Likewise, since I'm not psychologically connected in the right way to the dispersed remains of my burnt body - for instance, it doesn't have my memories-I wouldn't be identical to such a dispersed object. The second candidate answer is a physical criterion (see especially Olson (1999)).

\footnotetext{
${ }^{4}$ This commonsense intuition might seem to be in tension with the sort of Conventionalism that I attribute to the Zhuangzi on which we can exist as the scattered remains of our body. But we can address this apparent conflict by pointing out that our intuition is indeed true of ordinary cases: people don't normally have the sort of attitude that allows them to survive such a transformation. So we can say that commonsense is correct about such normal circumstances, we just shouldn't try to extend it to say that it's impossible to alter one's attitude in a way that allows one to survive in such a way.

${ }^{5}$ Here I take the term "entity" to apply to any sort of object—persons and non-persons, wholes and parts of wholes alike.
} 
On this view, one could say: the baby is the same biological organism as me, and is therefore identical to me; but the collection of dispersed ashes is not since it's not a biological organism, and so isn't identical to me.

To more clearly see that these are two different answers, rather than the same answer stated in two different ways, consider a teletransportation process much like that found in the western tv show Star Trek. Suppose the process works as follows: you step into an initial teletransportation machine on earth where the machine records all of your physical and psychological data, then the machine disintegrates you into your component atoms. Finally, a second receiving machine on, say, the moon, uses materials and molecules on the moon to create an exact physical and psychological duplicate of you. Now the question is this: did you survive the teletransportation trip? Those who hold the psychological view will answer "yes": the duplicate is psychologically continuous with you in the right way, and so is you. But those who hold the physical view will answer "no": the duplicate is not the same biological organism as you, which is evident from the fact that it's made from completely different atoms, hence the duplicate is not oneself. ${ }^{6}$ So which view is correct? Do I survive teletransportation or not?

The fact that there seems to be no real way to settle the debate has led many to the "Conventionalist" conclusion that the issue in part depends on one's person-directed attitudes ${ }^{7}$ see for instance, White (1989), Johnston (1989: 2010), Braddon-Mitchell and West (2001), Braddon-Mitchell and Miller (2004), Miller (2013), and Kovacs (2016; 2020). To illustrate, consider two communities. Those in the "Somataphile Community" believe they don't survive

\footnotetext{
${ }^{6}$ Of course, those who hold that physical view can hold that one's baby self and one's current self can be made of completely different atoms and yet still be identical, but this is only because the process was gradual enough to preserve physical identity between the two stages. In teletransportation, on the other hand, the process is abrupt.

${ }^{7}$ Conventionalists differ on which particular attitudes are relevant for determining one's survival conditions. For instance, Johnston emphasizes attitudes such as anticipation (Johnston 2010), Kovacs takes it to be one's beliefs (Kovacs 2016; 2020), and Braddon-Mitchell and Miller include attitudes concerning responsibility and property ownership (Braddon-Mitchell and Miller 2004).
} 
teletransportation, and have the corresponding person-directed attitudes: they fear teletransportation as death, they don't anticipate the experiences of the duplicate as being their very own experiences, etc. Those in the "Teletransporter Community", on the other hand, believe they survive and have the corresponding person-directed attitudes: they freely embrace teletransportation, treating it merely as a form of convenient and high-speed travel, they likewise anticipate the experiences of the duplicate as being their very own experiences, etc. Conventionalists hold that it's intuitive ${ }^{8}$ that neither community can be said to be wrong or mistaken; rather each community is correct on their own terms - the Somataphiles don't survive teletransportation, while the Teletransporters $d o .{ }^{9}$ And Conventionalists point to the difference in person-directed attitudes as accounting for the difference in survival conditions between the two communities. This is what Mark Johnston calls the "radical reversal" (Johnston 2010: 272). Roughly put, we ordinarily think that whether or not we survive an event should determine whether or not we should fear it as we do death, but on Conventionalism, matters are reversed-whether or not we fear a process as death determines whether or not we survive that process.

Here I should make one important clarification: Conventionalism does not claim that our attitudes can determine the physical facts, rather it's just a claim that our attitudes can determine the identity facts. For example, in the above teletransportation situation, the physical facts include the fact that you are disintegrated by the initial teletransportation machine on earth, then the receiving machine on the moon makes a physical and psychological duplicate of you out of atoms

\footnotetext{
${ }^{8}$ Some, such as Johnston (2010), Zimmerman (2012) and Kovacs (2016; 2020), base this intuition on a precommitment to a permissive ontology (such as a rich form of Four-Dimensionalism) on which, coinciding each person, there is both an object that survives teletransportation and an object that does not. If the plausibility of Conventionalism rested on such an ontology, it makes it less likely that Zhuangzi is a Conventionalist. But many other Conventionalists think the view is plausible even without an antecedent commitment to such a permissive ontology (see for instance Miller (2013); also White (1989) and Braddon-Mitchell and West (2001) make no appeal to such an ontology to motivate Conventionalism).

${ }^{9}$ Notice that this is not the claim that the communities' ways of life are equally beneficial. For the psychological community does have the advantage of high-speed travel.
} 
that weren't originally part of you in the initial machine. Conventionalism is not the claim that your attitudes can affect these physical facts. For instance, it does not claim that your attitudes can determine whether or not the duplication will succeed; if the device on the moon were to failinstead making, say, a person with different psychological features from you, or even just producing a fish, a flower, or failing to produce anything at all — this is just a fault of the machinery, rather than your attitudes. On the other hand, supposing that the teletransportation process were to successfully make a duplicate of you on the moon, Conventionalism does claim that your attitudes determine whether or not that duplicate on the moon is you. So it is the identity facts that Conventionalism claims is under the control of our attitudes, not the physical facts.

\section{Zhuangzi as Conventionalist}

I propose reading Zhuangzi as a Conventionalist. To begin to see why, I think the Conventionalist view fits well with Zhuangzi's tendency to take distinctions and divisions not as objective facts to be found in the world, but rather as originating from the mind. For instance, in chapter 2 "Discussion on Making All Things Equal (Qiwulun 齊物論)", Zhuangzi says:

Everything has its "that [bi 彼]," everything has its "this [shi 是]." From the point of view of "that," you cannot see it; but through understanding, you can know it. So I say, "that" comes out of "this," and "this" depends on "that"—which is to say that "this" and "that" give birth to each other.... Therefore the sage...recognizes a "this" but a "this" that is also "that" a "that" that is also "this." His "that" has both a right [shi] and a wrong [fei 非] in it; his "this," too, has both a right [shi] and a wrong [fei] in it. (Watson 2013: 10) 
Notice that the distinction between "shi" and "fei" here includes many layers of meaning: it's a distinction between what exists and what doesn't exist, what's correct and incorrect and also a distinction between what's good and bad (CHEN Jing (2001: 52) and CHEN Yun (2012: 44)). The Zhuangzi is thus pointing out that the sage doesn't make such absolute distinctions between such kinds of "shi" and "fei" because there are no such absolute distinctions to be found in the world. This is why Zhuangzi says "if discriminations are put into words, they do not suffice" and "those who discriminate fail to see" (Watson 2013: 14). Likewise Zhuangzi emphasizes the fact that such boundaries originate in the mind: "The Way has never known boundaries; speech has no constancy. But because of [the recognition of a] "this [shi]," there came to be boundaries" (Watson 2013: 13). Instead Zhuangzi admonishes us to give up distinctions altogether:

Right is not right; so is not so. If right were really right, it would differ so clearly from not right that there would be no need for argument. If so were really so, it would differ so clearly from not so that there would be no need for argument. Forget the years; forget distinctions. Leap into the boundless and make it your home! (Watson 2013: 17)

Likewise many commentators explicitly take the Zhuangzi to hold distinctions to be mind-made. For instance, CHEN Yun writes: "Things themselves don't have shi-fei, bi-ci (彼此) distinctions. Only when things are brought into relationship with people - on the basis of their epistemic perspective and examination-do such shi-fei, bi-ci distinctions exist" (Chen 2012: 44; my translation). And Kuang-Ming Wu comments: "the object-self (wo) is 'obtrusive' in that, as Kant said, it has its 'experience' only by imposing its synthetic-apriori forms on reality, on thing-in- 
itself.... The wo-self originates division (fen), a subjective regarding of the objects as different from the self..." (Wu 1990: 184-5).

So there is a strong emphasis in the Zhuangzi on the mind-dependence of divisions and distinctions. For this reason I don't think it would be surprising at all to find that the Zhuangzi holds a similar attitude concerning the divisions involved in personal identity-specifically boundaries demarcating when one exists and when that same entity ceases to exist. In fact, I think the Masters Yu and Lai passages quoted at the outset of this paper indicate that the Zhuangzi does indeed apply the mind-dependence of divisions to personal identity; for in those passages we see the Zhuangzi revising those divisions. To be clear, I'm not claiming that the Zhuangzi thinks our attitudes can determine the physical facts: that Master Yu's body at one point stops all its functioning, that his body eventually decays into the ground, and that his body's molecules later become integrated into, say, a rooster, cart-wheel or rat liver, are all facts that are determined by the world, rather than one's mind or attitudes. But I do think that for the Zhuangzi, the world itself does not determine where in that process lies the border that marks the point at which Master $\mathrm{Yu}$ ceases to exist; instead such an identity fact originates from our minds. That is why Master Yu can continue to exist even after his body has decayed and its composite molecules have dispersed. Ordinary people, because of their attitudes, cease to exist at death - that is, they cease to exist once their biological and psychological functions have stopped; but because personal identity facts are mind-dependent, Master $\mathrm{Yu}$ is able to revise or even do away with such divisions and survive his death.

So I propose reading Zhuangzi as a sort of Conventionalist. But we can see that Zhuangzi would hold a very peculiar and extreme sort of Conventionalism. For where Conventionalists typically assume that one can survive a process, so long as the process results in a person (such as a duplicate 
of oneself), Zhuangzi holds that Masters Yu and Lai can survive death as non-persons - such as roosters, cart-wheels, bug arms, etc. And they can survive in such an extreme way only because their attitudes differ from our ordinary attitudes in radical ways.

What are their radical attitudes? Master Yu tells us: "I received life because the time had come; I will lose it because the order of things passes on. Be content with this time and dwell in this order, and then neither sorrow nor joy can touch you. In ancient times this was called the 'freeing of the bound." (Watson 2013: 48) I take this attitude that is "free of the bound (xian jie 縣解)"10 to be further elucidated in various other passages (though if one disagrees with me on this point, one may use a different umbrella term to link them). For instance:

Master Si, Master Yu, Master Li, and Master Lai were all four talking together. "Who can look on nonbeing as his head, on life as his back, and on death as his rump?" they said. "Who knows that life and death, existence and annihilation, are all a single body? I will be his friend!"

The four men looked at one another and smiled. There was no disagreement in their hearts, and so the four of them became friends. (Watson 2013: 47)

Where most people look upon death as the end of their existence, these friends take it instead as a part of that existence. Also, from the passages quoted at the very beginning of this paper, we know that the four friends not only see the particular moment of death as part of their existence, but also the subsequent transformations that their corpse undergoes.

Further elucidating this unbound attitude, Master Lai explains:

\footnotetext{
${ }^{10}$ The term xian jie also appears in at the end of chapter 3 "The Secret of Caring for Life (Yangshengzhu 養生主)".
} 
When a skilled smith is casting metal, if the metal should leap up and say, "I insist on being made into a Moye!" he would surely regard it as very inauspicious metal indeed. Now, having had the audacity to take on human form once, if I should say, "I don't want to be anything but a man! Nothing but a man!" the Creator would surely regard me as a most inauspicious sort of person. So now I think of heaven and earth as a great furnace, and the Creator as a skilled smith. Where could he send me that would not be all right? (Watson 2013: 48-9)

In sum, Master Yu and Master Lai have an unbound attitude characterized by taking death and the resulting transformations as part of their existence, embracing whatever changes will occur to them — even disfiguration or death—not demanding that they remain in human form, but being all right with whatever new forms they encounter.

And this unbound attitude is echoed and praised in other parts of the Zhuangzi as well. We are told that the sage "delights in early death; he delights in old age; he delights in the beginning; he delights in the end." (Watson 2013: 45) Furthermore

The True Man of ancient times knew nothing of loving life, knew nothing of hating death. He emerged without delight; he went back in without a fuss. He came briskly, he went briskly, and that was all. He didn't forget where he began; he didn't try to find out where he would end. He received something and took pleasure in it; he forgot about it and handed it back again. (Watson 2013: 43) 
And in chapter 5 “The Sign of Virtue Complete (Dechongfu 德充符)" the Zhuangzi illustrates this attitude through Wang Tai, an ex-convict who had his leg chopped off, explaining "life and death are great affairs, and yet they are no change to [Wang Tai]. Though heaven and earth flop over and fall down, it is no loss to him.... As for things, he sees them as one and does not see their loss. He regards the loss of a foot as a lump of earth thrown away" (Watson 2013: 34-5).

So I suggest interpreting the Zhuangzi as holding that, in having an unbound attitude that embraces the transformations that one's body undergoes, one can survive death and the endless transformations thereafter. In other words, much as Conventionalists typically think the members of the Teletransporter Community survive teletransportation since they neither fear it nor try to avoid it, but rather embrace it and view their duplicate as a continuation of their existence, so Zhuangzi holds that those who are free from the bound survive death and the subsequent endless transformations since they neither fear nor try to avoid those transformations, but rather embrace them and see them as a continuation of their own existence.

\subsection{The wu-self and the wo-self}

I have already mentioned that Zhuangzi goes beyond standard forms of Conventionalism by holding a radical version of it. But another way in which Zhuangzi's Conventionalism is unique is in holding there to be different kinds of selves, not all of which can survive death. In chapter 2, Ziqi of South Wall claims that "I have lost myself (jinzhe wu sang wo 今者吾喪我)" (Watson 2013: 7). Though both "wu (吾)" and "wo (我)" are first-person pronouns, Zhuangzi here is treating them as referring to different selves. (There are also other first-person pronouns used throughout the 
Zhuangzi, but they seem closely interconnected with $w u$ and $w o .{ }^{11}$ ) One main difference between the $w u$-self and $w o$-self worth pointing out is their connection to social roles. DUAN Yucai 段玉裁, the commentator of the authoritative Chinese dictionary in the Han 漢 dynasty Explaining Graphs and Analyzing Characters (Shuowen Jiezi 說文解字), explains "when one is talking about oneself amongst others, the appropriate word for self-reference is $w o "$. In contrast, $w u$ was to be used in one's private thoughts when one thinks about oneself. For this reason, Thomas Ming takes the $w u$ self to be a "private-self" and the wo-self to be a "social-self" (Ming 2016: 61). CHEN Jing similarly takes the passage to be a reaction to the Confucian view that persons are defined in terms of the role they play in their web of relationships — such as the ruler-subject, father-son, husband-wife relationships (Chen 2001: 51). Chen explains that, for Zhuangzi, the wo-self corresponds to the Confucian self that is defined by those roles, but that the wo-self, in being so defined, loses its naturalness in carrying the burden of having to fulfill those roles (Watson 2013: 52). Consequently, being so characterized by artificiality, the wo-self is unable to achieve "you (遊)"—which for Zhuangzi is the highest state of freedom. On the other hand, the $w u$-self can extricate itself from the constraining roles of the wo-self, and draw closer to the state of you.

Given the above characterizations of the $w u$ - and $w o$-self, a Conventionalist interpretation of Zhuangzi should hold that it is the $w u$-self, and not the wo-self, that is able to survive death. One reason for this is that it's impossible to fulfill societal roles — such as being a good parent to one's child, or a good ruler to one's subjects - if one were a corpse, a rooster or a cart-wheel. So given

\footnotetext{
${ }^{11}$ For instance, in claiming that "the sage has no self (zhiren wuji 至人無己), "ji" is closely tied to the "wo" which one can lose. And in chapter 5, "wu" is used as closely synonymous with "yu (予)". For there in chapter 5, Liezi, a follower of Huizi, becomes convinced that the teachings of the shaman Ji Xian are greater than Huizi's own. On hearing Liezi's intoxication with the shaman, Huizi replies: "I have already showed you all the outward forms, but I haven't yet showed you the substance...try bringing your shaman along next time and letting him get a look at me (yushi 予示)." The shaman thus comes to visit Huizi on a number of occasions, and each time Huizi explains to Liezi what Huizi had shown of himself to the shaman, using the term "wushi 吾示" in each such explanation.
} 
that the wo-self is so defined by those social roles and death prevents the wo-self's fulfillment of those roles, death thereby also brings the destruction of the wo-self. On the other hand, since the $w u$-self isn't so characterized in this way, this leaves open the possibility that it exist even when unable to fulfill such social roles.

Similarly, we have already seen Kuang-Ming Wu's claim that "the wo-self originates division (fen), a subjective regarding of the objects as different from the self..." (Wu 1990: 185). Tied in with the Conventionalist reading, the idea then is that the wo-self is the one that has a bound attitude that takes death as marking the boundary between existence and non-existence. However, in losing the $w o$-self, the $w u$-self can broaden or completely do away with all such boundaries between itself and what comes before and after it. In this way the $w u$-self can survive death and participate in the transformations of the world.

\section{Clarifications and Objections}

Let me now make some clarifications about my reading and address some objections. One might object that the use of humor in the stories of Masters Yu and Lai indicate that Zhuangzi does not intend those stories to be taken literally. For instance, Master Yu speaking of his buttocks turning into wheels, or imagining Master Lai becoming a rat's liver might seem like playful examples not to be taken seriously. In response, I take the examples not as telling against a literal translation, but instead as expressions of an unbound attitude that welcomes death with playful ease and even giddy delight — for only those with a bound attitude would think death is something to be talked about solemnly and seriously. Furthermore, since those who are unbound welcome all the 
transformations they face, they likewise don't insist on being transformed into something noble and respectable, but delight even in becoming something as humble as a rat's liver.

A separate issue concerns what Zhuangzi thinks surviving as a rat's liver or cart-wheel is like. Do such things even have conscious experiences? That is, is Zhuangzi a sort of panpsychist? Some such as Brian Hoffert (2015), Eric Schwitzgebel (2018) and Jenny Hung (2019) think so. One passage in support of this claim is the story of Lady Li who wept when she was kidnapped, but regretted her tears when she discovered her new life was better than her former one; the text then asks "how do I know that the dead do not wonder why they ever longed for life?" (Watson 2013: 16). Another passage is taken from Master Lai's death bed monologue: "The Great Clod burdens me with form, labors me with life, eases me in old age, and rests me in death.... I will go off to sleep peacefully, and then with a start, I will wake up" (Watson 2013: 48-9). Though these might suggest a panpsychist reading, I think one can also reasonably resist such a reading. The Lady Li passage doesn't itself commit to the idea that the dead are able to have emotions such as regret, rather the passage only raises it as a conceptual possibility. Furthermore, one might take the moral of the story simply to be this: the state of being dead (even if it doesn't involve conscious experience) could be better than the state of being alive. Such a moral doesn't require panpsychism. As for Master Lai's death bed monologue, even if we deny a panpsychist reading, we can still hold that one can regain consciousness after death by becoming a conscious being such as a rooster or horse (or even just some part of their brain). Thus in saying "with a start, I will wake up" Master Lai might be referring to such phases in the process of transformation. So I think one can plausibly hold a non-panpsychist reading. Nonetheless, both the panpsychist and non-panpsychist views are compatible with a Conventionalist reading of the Zhuangzi. 
One might object that the extreme sort of Conventionalism that I attribute to the Zhuangzi is philosophically untenable. For instance, Mark Johnston argues that one couldn't transform into a non-person because non-persons don't have interests. As he says:

Only persons have interests in the relevant sense. In the sense of interest at hand, the sense that is relevant to identifying with some person as my "future self," only persons, that is, reflective intelligent beings that can consider themselves as themselves at various times and places, have interests.... The relevant disposition could not get a purchase on spiders, rainforests, crystals, or the like. (Johnston 2010: 277)

In other words, since

(a) one can only identify with something that has real interests, and

(b) only persons have such interests

it follows that one couldn't identify with non-persons. Therefore, if surviving as something requires identifying with it, then one couldn't survive as a non-person.

But I believe Zhuangzi would deny premise (a), holding it to just be a form of bound thinking. Just as Zhuangzi takes someone who says "I don't want to be anything but a man! Nothing but a man!" to be "a most inauspicious sort of person" (Watson 2013: 48-9), so Zhuangzi would hold the attraction of (a) as deriving from our desire to "be something with real interests! Nothing but something with real interests!" This deep-seated desire to cling to our status as reflective intelligent 
beings that have interests makes us averse to identifying with spiders, cart-wheels or rat livers. And it's easy to mistake this overwhelming desire as an indication that such identification is impossible. But I take the Zhuangzi instead to be suggesting that, contrary to (a), we can indeed identify with such non-persons by unbinding ourselves from a narrow-minded unwillingness to let go of the familiar.

Another objection one might have with my reading is that it's incompatible with Zhuangzi's other teachings concerning the self. For instance, after Zhuangzi's wife died, Zhuangzi said

I looked back to her beginning and the time...before she had a spirit. In the midst of the jumble of wonder and mystery, a change took place and she had a spirit. Another change and she had a body. Another change and she was born. Now there's been another change and she's dead. It's just like the progression of the four seasons: spring, summer, fall, winter. (Watson 2013: 141)

There are two different kinds of objection one might raise to the Conventionalist reading in connection with this passage. The first objection is this: here Zhuangzi indicates that, just as the change in seasons is inevitable and occurs regardless of one's attitudes, so the changes that occur to one's body — including death — are inevitable and occur regardless of our attitudes. One might think this is in tension with the Conventionalist view. But this objection only arises if one overlooks the distinction between physical and identity facts. For the Conventionalist can agree that the physical changes that happen to oneself happen regardless of one's attitudes since Conventionalism is just the claim that our attitudes determine the identity facts. In other words, Zhuangzi doesn't need to know anything about his wife's attitudes to know whether or not she has 
died. If she hasn't taken a breath and her heart hasn't beaten for over a week, then she is indeed dead-no need to consult her attitudes. But whether she still exists as the dead corpse or as any number of other things does require an understanding of her attitudes.

A second objection that might arise in connection with this passage is more subtle. The objection says: if Zhuangzi truly is a Conventionalist, then we should expect Zhuangzi here to mention that his wife existed prior to her acquiring a body and/or that she continued to exist after she died. Yet Zhuangzi doesn't mention either of these things. ${ }^{12}$ In response, we should first recognize that this story belongs to the outer chapters, and so we should be extra hesitant in assuming that it was penned by the same author that penned the stories of Masters Yu and Lai. But even if we make this assumption there are a couple possible responses we could make. One is to hold that even if Zhuangzi didn't believe his wife survives death, this is only because he realized she didn't have the right attitudes; so Zhuangzi had to cope with her death in a different way. Alternatively, we can read the passage not as denying that his wife survived death, but as presenting Zhuangzi's own self-treatment of his bound attitude towards her death. For Zhuangzi realized that in mourning her death, he himself was clinging to her human form. And the way to treat and avoid such clinging isn't through the reminder that his wife survives, but is primarily carried out through the recognition of the naturalness of the endless changes of the world. In other words, though recognizing that she survives could help treat Zhuangzi's grief, Zhuangzi is here

\footnotetext{
12 Though Watson's translation says "a change took place and she had a spirit. Another change and she had a body" (Watson 2013:141; emphasis mine), thus suggesting that she existed prior to her birth, the original Chinese doesn't employ a pronoun such as "she": bian er you qi, qi bian er you xing 變而有氣, 氣變而有形. Also, had Zhuangzi used, the term hua (化) here, that might have indicated that Zhuangzi takes it to be the same entity that persists through all the changes (this is, at least, how Xunzi 荀子 in his “Rectifying Names (Zheng Ming 正名)" understands the term: "Something which has its form changed but in reality is the same, this is called hua (zhuangbian er shi wubie er weiyizhe weizhi hua 狀變而實無別而為異者謂之化)”. The word bian (變), however, is the term that Zhuangzi actually uses, which might not seem to have this same implication.
} 
recognizing that the fundamental problem isn't his grief, but his bound attitude - a problem that requires a very different kind of treatment.

To better understand my Conventionalist reading of the Zhuangzi, let me compare it to A.C. Graham's:

The liberation from selfhood is seen above all as a triumph over death. [Zhuangzi's] position is not that personal consciousness will survive death, rather that in grasping the Way one's viewpoint shifts from 'I shall no longer exist' to something like 'In losing selfhood I shall remain what at bottom I have always been, identical with all the endlessly transforming phenomena of the universe.' (Graham 1989: 202)

I assume that, by "losing selfhood", Graham doesn't mean to say that one ceases to exist, but only has in mind the attitude of not clinging to a particular form or state-such as having a healthy undisfigured body or being human. (Though if he instead means that one ceases to exist, or that there is no self to begin with, then the view is obviously quite different from my own.) Given this assumption, Graham interprets the Zhuangzi as saying that in death, one continues to exist as "all the endlessly transforming phenomena of the universe" (Graham 1989: 202). This is different from my own Conventionalist interpretation since mine doesn't imply that one is necessarily identical with all the transformations of the universe, but might only be identical to some of those transformations. My interpretation allows for this possibility since people can have different attitudes; for even if one embraces death as part of their own existence, it's still open to them whether they will identify with the transformations of the entire universe - and so hold that "the ten thousand things are one with me (wanwu yu wo wei yi 萬物與我為一)" (Watson 2013: 13)—or 
just identify with the transformations of a particular part of it. And I take this feature of my account to have textual backing. For Master Yu only identifies with the transformations that his body undergoes - such as his left arm turning into a rooster, or his right arm turning into a crossbow pellet - rather than the transformations of the entire universe. Master Lai likewise isn't thought of as transforming into a whole bug, but just its arm, nor is he thought of as transforming into an entire rat, but just its liver.

A final point of clarification about my account is that I do not intend to claim that the survival of death is the primary or only goal for Zhuangzi. One who takes a Conventionalist interpretation of Zhuangzi can still agree that Zhuangzi has other aims as well. For instance, as LUO Anxian explains, for Zhuangzi "the ordinary person's sorrow, the ordinary person's fatigue, the ordinary person's confusion, these problems are where Zhuangzi's concern lies" (Luo 2013: 57; my translation). And Kuang-Ming Wu says "to live rightly is neither living redemptively (Jesus) nor living enlightenedly (Buddha), but living appropriately, that is, fittingly to the changing climate of things, now soaring, now roaming - and that is [Zhuangzi's] central concern" (Wu 1990: 81). Similarly, BAI Ruifen explains that, for Zhuangzi, "the 'heart-mind's highest realm is a pure and simple kind of free and natural state...one that shouldn't have a differentiation of 'merit points' nor the excessive miscellany of nobility and lowliness" (Bai 2012: 119; my translation). The Conventionalist reading of Zhuangzi is compatible with holding that Zhuangzi takes such a free and natural state to be the highest state; likewise, we can hold that Zhuangzi employs various therapeutic techniques - especially those in chapter 2 that have us doubt whether our shi-fei distinctions represent reality - are aimed at helping the ordinary person achieve such a state. My only claim is that Conventionalism is one aspect of Zhuangzi's larger vision that has gone ignored. 
Likewise, Zhuangzi's therapeutic techniques not only help bring us into such a state of spiritual freedom, but they also help us to survive death by freeing us from the bound.

\section{Further Connections}

In this section I will draw out further connections between my Conventionalist reading of the Zhuangzi and other parts of the text, for this interpretation could help cast light upon or open up alternative interpretations of other passages. Though there are numerous passages that can be incorporated in this way, I will restrict my discussion to four.

The first two passages I will look at both seem to portray the Conventionalist idea that by altering one's attitudes one also alters one's survival conditions. The first of these is found near the end of chapter 6 :

Yan Hui said, "I'm improving!"

Confucius said, "What do you mean by that?"

"I've forgotten benevolence and righteousness!"

"That's good. But you still haven't got it."

$\cdots$

Another day, the two met again, and Yan Hui said, "I'm improving!"

"What do you mean by that?"

"I can sit down and forget everything!"

Confucius looked very startled and said, "What do you mean, sit down and forget everything?" 
Yan Hui said, "I smash up my limbs and body, drive out perception and intellect, cast off form, do away with understanding, and make myself identical with the Great Thoroughfare. This is what I mean by sitting down and forgetting everything."

Confucius said, "If you're identical with it, you must have no more likes! If you've been transformed, you must have no more constancy! So you really are a worthy man after all! With your permission, I'd like to become your follower." (Watson 2013: 52-3)

This seems to indicate that a change in one's attitudes can lead to a change in one's identity or survival conditions. For in sitting and forgetting, Yan Hui becomes "identical with the Great Thoroughfare (tongyu datong 同於大通)" and therefore survives the transformations of the world. This metaphysical change is emphasized when Confucius says "if you've been transformed, you must have no more constancy! (hua ze wuchang ye 化則無常也)" I take Confucius here, who is speaking on behalf of Zhuangzi, as holding that the ordinary person is constant because, from the beginning to the end of their existence, they are a human. Yan Hui's existence, on the other, is not so confined to the stages where he is a human, and so is inconstant.

A similar account is found just prior to the stories of Masters Yu and Lai. There we have an account of Buliang Yi who undergoes a gradual multi-week process of learning the way of a sage. After some training he was able to "put the world outside himself.... after that he was able to put life outside himself... and after he had done away with past and present, he was able to enter where there is no life and no death" (Watson 2013: 46). Like the Yan Hui passage above, I also take this story as portraying Buliang Yi as becoming identical to the Great Thoroughfare of which all things are a part, and likewise as illustrating the sort of Conventionalism I have been defending. For the story not only describes the alteration of Buliang Yi's attitudes—where the process of putting 
things outside of himself describes the freeing of the bound-but also explains that the change in those attitudes subsequently leads to Buliang Yi's survival of death—for at the end of the process he "was able to enter where there is no life and no death (而後能入於不死不生)".

One might question this reading since entering where "there is no life" seems to indicate a mysterious state of existence that transcends the state of being alive, and so is describing something quite different than the sort of "earthly" existence I have been concerned with (see Roth (2000) for this sort of interpretation). But, in response, we could instead interpret "sheng (生)" not as the state of living, but only as one's coming to be. Thus where "si (死)" is used to indicate the end of one's existence and "sheng" is used to indicate its beginning, the passage tells us that Buliang Yi was able to attain a state where his existence has neither end nor beginning - instead existing both through the beginningless past and endless future by means of the ongoing transformations of the Great Thoroughfare. ${ }^{13}$ Similarly, I interpret the passage immediately following (shashengzhe bu si, shengshengzhe bu sheng 殺生者不死，生生者不生) as: “that which kills life doesn't cease to exist, and that which brings life into being doesn't come to be". I take this also to be a description of the Great Thoroughfare, which neither comes into nor out of existence, but gives life and brings death to all living things. (See Wang (2000: 347-8) for further evidence that Zhuangzi takes the world to be without beginning or end.) Though my Conventionalist reading of the Master Lai and

\footnotetext{
${ }^{13}$ It might seem strange that one's current attitudes can determine when —or even if —one came into existence in the past. For even if we can alter or affect the future we tend to think the past cannot be changed. In response, it's good to keep in mind that the claim is not that our attitudes can affect the past physical facts - such as past qualitative facts and facts about the arrangement of mass-energy in the past; rather the claim is only that those attitudes can affect past identity facts - such as whether there was a point in the past at which Buliang Yi came into existence and where that point lies if there is such a point. Though most have a forceful intuition that we cannot affect past physical facts, I think there's room to embrace the idea that we can affect past identity facts. And, in fact, Conventionalists tend to embrace such an idea — see for instance Braddon-Mitchell and White (2001: 68), Zimmerman (2012: 124) and Kovacs (2020: sect. 3.1).
} 
Master $\mathrm{Yu}$ passages doesn't require that we also read this passage as relating to Conventionalism in the above way, it does make such a reading attractive.

Let's now turn to another passage, returning to the story of Master Lai in which: "Gasping and wheezing, [Master Lai] lay at the point of death. His wife and children gathered round in a circle and began to cry. Master Li, who had come to ask how he was, said, 'Shoo! Get Back! Don't disturb the process of change!"' (Watson 2013: 48). It's quite striking that Master Li not only drives out the grieving family, but does so in such a rude and excessive way. But if my Conventionalist reading is right, there is a very good reason for his strange behavior. For the grief of Master Lai's wife and children might influence Master Lai's own attitudes, tempting him to resist or regret his transformation resulting in a bound attitude. On Conventionalism, such a change in attitudes would be detrimental to Master Lai's survival of the process. Master Li's actions are therefore not mere boorishness, but are instead an urgent response to a detrimental situation, a response that is crucial for preserving Master Lai's survival of his impending death. This further highlights the importance of living in community with like-minded people who can come to each other's aid in such a way. The Zhuangzi portrays Masters Si, Yu, Li and Lai as becoming friends upon discovering the unity of their attitudes towards death (Watson 2013: 47), this is also portrayed in the friendship of Masters Sanghu, Fan and Qinzhang (Watson 2013: 49). On Conventionalism, such community becomes crucial not only for maintaining one's attitudes, but also for the preservation of the survival of one's death.

Finally, let me connect my Conventionalist reading with the famous butterfly dream that appears at the end of Chapter 2: 
Once Zhuang Zhou dreamed he was a butterfly, a butterfly flitting and fluttering around, happy with himself and doing as he pleased. He didn't know he was Zhuang Zhou. Suddenly he woke up, and there he was, solid and unmistakable Zhuang Zhou. But he didn't know if he were Zhuang Zhou who had dreamed he was a butterfly or a butterfly dreaming he was Zhuang Zhou. Between Zhuang Zhou and a butterfly, there must be some distinction! This is called the Transformation of Things. (Watson 2013: 18)

The passage is quite peculiar because it raises an epistemological issue- - "he didn't know if he were Zhuang Zhou who had dreamed he was a butterfly or a butterfly dreaming he was Zhuang Zhou"— but draws an ontological conclusion—-between Zhuang Zhou and a butterfly, there must be some distinction! This is called the Transformation of Things." On a Conventionalist reading, we can connect the epistemological and the ontological elements via our psychological attitudes. That is, the epistemological issue is raised as a therapeutic technique for adopting an attitude of being free from the bound; and Zhuangzian Conventionalism implies that such psychological freedom brings with it our own survival of death and, hence, our transformation into different beings.

This reading is similar to what Robert Allinson calls the "external transformation" interpretation, on which the passage is read as pointing to the ontological transformations that occur in the world (Allinson 1989: 89). This Allinson contrasts with, first, the confusion interpretation on which the text is drawing the skeptical conclusion that we can't know whether we're awake or dreaming, and second, Allinson's own self-transformation interpretation (which also involves a re-ordering of the text) in which the story points to one's transformation to a more enlightened state. Against the external transformation interpretation, Allinson raises a number of objections (see Allinson 1989; 
2012). Though I largely agree with Xiaomei Yang's (2005) replies to those objections, I think that there is more that can and should be said against Allinson's objection that the interpretation's conclusion is too weak. ${ }^{14}$ His objection is as follows:

We do not need to have recourse to a dream metaphor to arrive at the awareness that things are constantly changing from one to another. If our only concern is transience, we do not need any sort of awakening to become aware of this transience. We would not first have to go through some puzzle involving a confusion of reality with illusion. We would only have a philosopher's lament about the brevity of existence. We would not mistake what is for what is not. The butterfly dream would serve as an inapposite metaphor for a complaint about the constant succession of things in the world.... (Allinson 1989: 89)

On my Conventionalist reading, however, there's very good reason to appeal to a butterfly dream. Since the goal is to help us embrace the idea of surviving in forms wildly different than one's human form, dreaming that one is a butterfly is strongly conducive towards that end. For in such a dream, one believes oneself to be a butterfly and likewise completely forgets one's human formjust as Zhuang Zhou "didn't know he was Zhuang Zhou". One might object that this still doesn't explain why Zhuangzi needs to appeal to a dream state — why not just have Zhuang Zhou imagine that he was a butterfly? But, in response, there's a good reason for this, for in a dream (rather than in mere imagination) one is completely immersed in the experience and is completely convinced

\footnotetext{
${ }^{14}$ To this objection, Yang concedes that "we do not have to appeal to a dream to express the idea that everything is in a state of endless change" (Yang 2005: 257). She instead responds that the objection can be turned against Allinson's own interpretation as well.
} 
that one is the butterfly. ${ }^{15}$ The psychological impact and ability to free one from the bound would therefore be much greater than if one were to merely imagine it. But why does the passage mention that after awaking Zhuang Zhou "didn't know if he were Zhuang Zhou who had dreamed he was a butterfly or a butterfly dreaming he was Zhuang Zhou"? I take this also to be a therapeutic tool. For in waking up from the dream, we might easily forget the mindset that we had therein. But in reflecting on the idea that even now one might be that butterfly, we are powerfully reminded of our psychological state in the dream, consequently the dream's potential to unbind us is amplified.

So Allinson is surely correct that "we do not need to have recourse to a dream metaphor to arrive at the awareness that things are constantly changing from one to another". But on my interpretation, since the goal is not the mere recognition that things change, but instead the alteration of our very survival conditions, appealing to and reflecting upon such dream experiences turns out to be a powerful everyday tool for allowing us to attain such an end. Furthermore, contrary to Thomas Ming's suggestion that the value of the story can be equally captured if the dream were instead of a human or a martian (Ming 2012: 499), it's crucial that the dream be of a butterfly or some other form radically different from our own. For since the latter sorts of experiences are of existing in a radically different way, they have much greater potential for freeing us from our attachment to our human form and setting us on the path to becoming free from the bound.

\section{Conclusion}

\footnotetext{
${ }^{15}$ But we should keep in mind, as Lee reminds us, there are limits to how closely the dream can match the actual experience of the butterfly (Lee 2007: 193-4).
} 
I have argued for a Conventionalist reading of the Zhuangzi on which, by radically changing our attitudes, we can survive our death and persist through the endless transformations of the world. Where in envisioning Masters Yu and Lai as surviving as a rooster or a rat's liver, it's tempting to interpret this as a mere flight of imagination or a way of pretending — one might even worry that it's a sort of delusion. But on the Conventionalist reading there's nothing delusional or fictional about it. In adopting an unbound attitude that embraces the endless transformations of the world, one can rationally and whole-heartedly exclaim: "How marvelous the Creator is! What is he going to make out of you next? Where is he going to send you?" (Watson 2013: 48).

Acknowledgements Many thanks to Jenny Hung, OUYANG Xiao, SHEN Ting, and two anonymous reviewers from

Dao for excellent feedback on the paper. Thanks also to Mary Bockover and audience members from the Society for Asian and Comparative Philosophy Conference 2019 for early discussions on this topic.

\section{References}

Allinson, Robert E. 1989. Chuang-Tzu for Spiritual Transformation: An Analysis of the Inner Chapters. Albany: SUNY press.

Allinson, Robert E. 2012. “Snakes and Dragons, Rat's Liver and Fly's Leg: The Butterfly Dream Revisited.” Dao: A Journal of Comparative Philosophy, 11, 513-520.

BAI, Ruifen 白瑞芬. 2012. “I have lost myself’ Zhuangzi’s Absolute State of Spiritual Freedom ‘吾丧我'庄子心灵 自由的绝对境界.”湖北社会科学, 5, 118-120.

Berkson, Mark. 2019. "Death in Ancient Chinese Thought: What Confucians and Daoists Can Teach Us about Living and Dying Well." In Death and Dying: An Exercise in Comparative Philosophy of Religion, edited by Timothy D. Knepper, Lucy Bregman, Mary Gottschalk. Switzerland: Springer. 
Bockover, Mary I. 2020. “Two Portrayals of Death in Light of the Views of Brentano and Early Daoism.” In Daoist Encounters with Phenomenology: Thinking Interculturally about Human Existence, edited by David Chai. New York: Bloomsbury.

Braddon-Mitchell, David \& Caroline West. 2001. “Temporal Phase Pluralism.” Philosophy and Phenomenological Research, LXII(1), 59-83.

Braddon-Mitchell, David \& Kristie Miller. 2004. "How to be a Conventional Person.” The Monist, 87(4), 457-474.

CHEN, Yun 陈望武. 2012. 'From 'the knowledge of shi-fei' to 'the best thing to use is clarity': the epistemic process via the ascension from 'knowledge' to 'virtue'—with a focus on the Zhuangzi's Qiwulun 从'是非之知'到'莫若 以明'：认识过程由'知'到'德'的升进——以《庄子·齐物论》为中心.” 天津社会科学, 3, 40-46.

CHEN, Jing 陈静. 2001. “I have Lost Myself-An Explanation of the Zhuangzi's Qiwulun 吾丧我一《庄子.齐物 论》解读." 哲学研究, 5, 49-53.

Chong, Kim-chong. 2016. Zhuangzi's Critique of the Confucians: Blinded by the Human. Albany: SUNY Press.

Graham, A. C. 1989. Disputers of the Tao: Philosophical Argument in Ancient China. La Salle: Open Court.

Hoffert, Brian. 2015. “Beyond Life and Death: Zhuangzi's Great Awakening.” Journal of Daoist Studies, 8, 165178.

Hung, Jenny. 2019. "The Theory of the Self in the Zhuangzi: A Strawsonian Interpretation.” Philosophy East and West, 69(2), 376-394.

Johnston, Mark. 1989. "Relativism and the Self." In Relativism: Interpretation and Confrontation, edited by Michael Krausz. Notre Dame: University of Notre Dame Press.

Johnston, Mark. 2010. Surviving Death. Princeton, N.J.: Princeton University Press.

Komjathy, Louis. 2013. The Daoist Tradition: An Introduction. London: Bloomsbury.

Kovacs, David Mark. 2016. “Self-Made People.” Mind, 125, 1071-1099.

Kovacs, David Mark. 2020. “Diachronic Self-Making.” Australasian Journal of Philosophy, 98(2), 349-362.

Lee, Jung H. 2007. "What is it Like to be a Butterfly? A Philosophical Interpretation of Zhuangzi's Butterfly Dream.” Asian Philosophy, 17(2), 185-202.

Lee, Jung H. 2014. The Ethical Foundations of Early Daoism. New York: Palgrave MacMillan. 
Liu, Xiaogan. 2015. “Zhuangzi's Philosophy: A Three Dimensional Reconstruction.” In Dao Companion to Daoist Philosophy, edited by Xiaogan Liu. Dordrecht: Springer.

Locke, John. 1694. An Essay Concerning Human Understanding.

LUO, Anxian 罗安宪. 2013. “An Explanation of the Zhuangzi’s 'I have Lost Myself’ 庄子'吾丧我'义解.”哲学研究, 6, 54-78.

Miller, Kristie. 2013. “"Personal Identity’ Minus the Persons.” Philosophical Studies, 166, S91-S109.

Ming, Thomas. 2012. "Sleeping Beauty and the Dreaming Butterfly; What did Zhuangzi Doubt About?.” Dao: Journal of Comparative Philosophy, 11, 497-512.

Ming, Thomas. 2016. "Who Does the Sounding? The Metaphysics of the First-Person Pronoun in the Zhuangzi." Dao: Journal of Comparative Philosophy, 15, 57-79.

Olson, Eric T. 1999. The Human Animal: Personal Identity without Psychology. Oxford: Oxford University Press.

Parfit, Derek. 1984. Reasons and Persons. Oxford; New York: Clarendon Press.

Roth, Harold. 2000. “Bimodal Mystical Experience in the 'Qiwulun' Chapter of Zhuangzi.” Journal of Chinese Religions, 28(1), 31-50.

Schwitzgebel, Eric. 2018. "Death, Self, and Oneness in the Incomprehensible Zhuangzi.” In The Oneness Hypothesis: Beyond the Boundary of the Self, edited by Philip J. Ivanhoe. New York: Columbia University Press.

Valmisa, Mercedes. 2015. "Beyond our Control? Two Responses to Uncertainty and Fate in Early China.” In New Visions of the Zhuangzi, edited by Livia Kohn. St. Petersburg: Three Pines Press.

Wang, Youru. 2000. "Philosophy of Change and the Deconstruction of Self in the Zhuangzi." Journal of Chinese Philosophy, 27(3), 345-360.

Watson, Burton. 2013. The Complete Works of Zhuangzi. New York: Columbia University Press.

White, Stephen L. 1989. “Metapsychological Relativism about the Self.” Journal of Philosophy, 86(6), $298-323$.

Yang, Xiaomei. 2005. "Great Dream and Great Awakening: Interpreting the Butterfly Dream Story." Dao: Journal of Comparative Philosophy, 4(2), 253-266.

Zimmerman, Dean. 2012. "Personal Identity and the Survival of Death.” In The Oxford Handbook of Philosophy of Death, edited by Ben Bradley, Fred Feldman, Jens Johansson. Oxford: Oxford University Press. 